\title{
DE JUEGOS Y METÁFORAS HACIA UNA FILOSOFÍA DE LA EDUCACIÓN CON ROSTRO DE NIÑEZ
}

\author{
Juan Pablo Espinosa Arce \\ Recibido: 14.07.2017 Aceptado: 05.12.2017
}

\begin{abstract}
RESUMEN

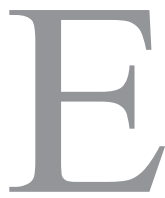

L PRESENTE ARTÍCULO BUSCA ASUMIR UNA FILOSOFÍA DE LA EDUCACIÓN QUE DÉ ESPACIO a nuevas formas de conocimiento de la realidad a partir de la mediación de lo lúdico, las metáforas y la imaginación. Como hipótesis de trabajo sostenemos que dichos elementos posibilitan la construcción de prácticas educativas, sociales y culturales que permiten reconocer en el rostro de la niñez el inicio de una nueva episteme y sociedad que dan mayor espacio a la sensibilidad, a las preguntas y a la creatividad. De esta manera, se evidenciará la superación de ciertas prácticas educativas monológicas, encorsetadas y que no dan cabida a la sorpresa de lo que surge desde los juegos y metáforas de la infancia.
\end{abstract}

Palabras clave: Imaginación, filosofía de la educación, niñez, preguntas, creatividad

\section{OF GAMES AND METAPHORS \\ TOWARDS A PHILOSOPHY OF EDUCATION WITH A CHILD'S FACE}

\begin{abstract}
The present article seeks to assume a philosophy of education which gives space to new forms of knowledge of reality from the mediation of the ludic, metaphors and imagination. As a working hypothesis, we argue that these elements enable the

1 Licenciado en Educación y Profesor de Religión y Filosofía por la Universidad Católica del Maule. Magíster en Teología Fundamental por la Pontificia Universidad Católica de Chile. Docente del Instituto Profesional Santo Tomás, Sede Rancagua. Correo: jpespinosa@uc.cl
\end{abstract}


construction of educational, social and cultural practices that allow the recognition of the beginning of a new episteme and a new society in the children's face, that give greater space to sensitivity, questions and creativity. In this way, it will be evident the overcoming of certain monological educational practices, which are not limited to the surprise of what arises from the games and metaphors of childhood.

Keywords: Imagination, philosophy of education, childhood, questions, creativity

\section{INTRODUCCIÓN}

El pedagogo chileno Antonio Faúndez, en diálogo con Paulo Freire, comenta: "yo insistiría en que el origen del conocimiento está en la pregunta, o en las preguntas, o en el acto mismo de preguntar; y me atrevería a decir que el primer lenguaje fue una pregunta, la primera palabra fue, al mismo tiempo, pregunta y respuesta en un acto simultáneo" (Faúndez - Freire 2014, 72). La pregunta nos abre al conocimiento del mundo, y ella es una de las formas más auténticas del proceso de enseñanza y aprendizaje. Preguntar significa admirarse de las cosas que ocurren en la realidad: ¿por qué hay sol y por qué está la luna? ¿por qué a veces sentimos calor y otras veces frío? ¿qué es el bien? ¿dónde está Dios? ¿qué es la muerte y la vida? Estas son las preguntas que dieron origen histórico a la filosofía como ciencia de la totalidad, como disciplina que buscó interrogar por todo lo que acontecía en la realidad. Con ello, la filosofía acontece como un acto de curiosidad constante, de asombro, de maravillarse ante lo que ocurre y ante lo que nos ocurre.

Por ello Paulo Freire continuamente, y más en este diálogo con Faúndez, insiste en la necesidad de volver recreativamente sobre la pregunta. Por ello sostiene: "vuelvo a insistir en la necesidad de estimular en forma permanente la curiosidad, el acto de preguntar, en lugar de reprimirlo. Las escuelas rechazan las preguntas o bien burocratizan el acto de preguntar. La existencia humana está, porque se hizo preguntando, en la raíz de la transformación del mundo" (Faúndez - Freire 2014, 75). La pregunta está en la base de la creación de realidad y en la transformación del mundo. El conocimiento, mediado por la pregunta, tiene una consecuencia política, en cuan- 
to abre posibilidades nuevas para articular una renovada episteme y no mantener lo burocrático de las respuestas que se realizan a preguntas inexistentes.

Y dentro del juego de la pregunta y de la respuesta podemos identificar, como en un lugar central, el rol protagónico de los niños y niñas. Ellos son los grandes formuladores de preguntas, y con esas preguntas desafían al mundo adulto a responder de manera que puedan ir saciando su apetito de conocimiento. Es más, esta capacidad del asombro infantil es una de las conditio sine qua non para hacer un auténtico trabajo filosófico. En esto, autores como García Morente reconocen que "para abordar la filosofía, para entrar en el terreno de la filosofía, una primera disposición de ánimo es absolutamente indispensable. Es absolutamente indispensable que el aspirante a filósofo se haga bien cargo de llevar a su estado una disposición infantil, el que quiere ser filósofo necesitará puerilizarse, infantilizarse, hacerse como el niño pequeño" (García Morente 1988, 22).

No deja de ser llamativo, y de hecho es una ruptura epistemológica, que Morente considere que el paradigma del auténtico filósofo es el niño pequeño. Aquí entramos en un terreno nuevo, en cuanto que la infancia es puesta como modelo de aquella etapa de la vida en donde aparecen las primeras y más fundamentales interrogantes sobre la vida y sus dinamismos. Las preguntas nos abren un mundo nuevo. Y creemos que desde ellas debería cursar la filosofía de la educación con rostro de niñez.

En las preguntas de los niños y niñas acontece el despunte de algo nuevo. Una puerta se abre a formas de conocimiento y de integración con el medio que están motivadas por la imaginación, por el juego y por un sentido de gratuidad. En palabras de Panotto, "cuando compartimos con niños y niñas, nos asombramos de sus cambios repentinos, del poder de su imaginación, de la manera de construir un juego en los espacios y con los elementos menos pensados, de la forma de mezclar ideas, discursos y conceptos de las maneras más sorprendentes y originales" (Panotto 2016, 9).

Estos conceptos están asumidos desde la libertad, la creatividad, el asombro, la imaginación y el juego. No son conceptos secos o encorsetados, al contrario, son libres, amplios, con sentido de corporalidad, de sentimientos, de sueños y risas. Y es desde 
aquí que queremos postular la tesis de nuestra propuesta: los elementos del juego, las metáforas, la poética, la imaginación nos permiten construir una renovada filosofía de la educación que aporte herramientas legítimas para pensar nuestros procesos educativos con la niñez. Es por ello que hablamos de una reflexión filosófica educativa con rostro de niños y niñas. Creemos y apostamos por una reflexión más integral e integradora, con más sentido de realidad, de ruptura y de propuesta. Los niños desbaratan las seguridades del mundo adulto. Nos sorprenden y nos invitan a la sorpresa y a construir, como artesanos y en comunidad, el conocimiento.

Para efectos metodológicos seguiremos la pista a autores como P. Ricoeur, R. Alves, G. Agamben y G. Bachelard que proponen la cuestión del estatuto epistémico de la metáfora, lo lúdico, el lenguaje y la imaginación como racionalidad filosófica, educativa y antropológica. Volvemos, con ello, a la importancia de la poética en la construcción de una pedagogía y de una reflexión filosófica relevante para el trabajo educativo. A partir de ello, mostramos la importancia del juego de los niños como producción de sentido y espacio de encuentro; posteriormente abordamos la cuestión de la metáfora y de la imaginación poética en la formulación de una renovada episteme filosófica; finalmente, y a modo de conclusión abierta, algunas pistas para seguir pensando el trabajo filosófico y pedagógico con la infancia y desde la infancia.

\section{EL RETORNO A LA METÁFORA COMO RACIONALIDAD FILOSÓFICA}

El tema de la metáfora constituye un aspecto recurrente en la reflexión filosófica y hermenéutica actual. Reconocidos son los aportes de Paul Ricoeur en torno a la metáfora, a los símbolos y al excedente de sentido que estos elementos lingüísticos poseen en contraposición a lo que él denomina el lenguaje metafórico muerto. Autores como C. Carbullanca comenta que el retorno a la poesía, al mito, a la metáfora, representa el surgimiento de una nueva racionalidad y de una comprensión de lo que es un texto, no solo el escrito, sino que también el espacio, la cultura, la música o el arte. A su juicio "los sueños, la cultura, la praxis, la obra de arte son susceptibles de ser textos en la elaboración de este nuevo paradigma de texto está 
fundado sobre los estudios interdisciplinares lingüísticos, antropológicos y estéticos" (Carbullanca 2014).

La metáfora constituye un momento de "amplitud del campo de la teoría de la interpretación” (Ricoeur 2006, 58). Hay un excedente de sentido en las metáforas. Tiene que ver con lo poético, lo estético y las nuevas formas de comprensión de la realidad. Y por ello asumimos que ella tiene una fuerte vinculación con la infancia. Es más, autores como Michel de Certeau declaran que la infancia es "una fábula que hace crecer" (De Certeau 2006, 291). Para este autor la infancia representa un retorno y una invención, algo que viene de otro lugar, algo que altera y desbarata las formas tradicionales de conocimiento. En palabras de De Certeau, "el in-fans es el acontecimiento en la inversión o en la alteración que le responde. Ese acontecimiento que carece de un lugar social o racional solo puede decirse en sueños. Es la metáfora de una cuestión del sujeto y, como tal, no introducible en las racionalidades o en las organizaciones de una sociedad; y todavía, esta metáfora conserva una forma interrogativa" (De Certeau 2006, 292).

La infancia no puede enclaustrarse en determinadas formas preconcebidas de educación o filosofía. La infancia es siempre mayor, por ello es metáfora, porque excede el sentido de su formulación o de su sentido original. Hay un enfrentamiento entre el sentido literal y el sentido emotivo de la metáfora, y en ello es donde acontece la llamada metáfora viva como "creación instantánea, una innovación semántica que no tiene reconocimiento en el lenguaje establecido, y que solo existe debido a la atribución de un predicado inusual o inesperado" (Ricoeur 2006, 62). Creemos que pensar una filosofía de la educación, una práctica educativa desde la infancia, nos permite reconocer cómo lo nuevo irrumpe con fuerza en la construcción del conocimiento. La infancia, como realidad y como metáfora que excede el sentido, representa la inauguración de una sociedad cualitativamente distinta, como una revolución de lo pequeño, de lo silencioso pero que no es mudo. Podríamos aventurar una especie de mutismo significativo en el relato lúdico de la infancia. Por ello, es que Ricoeur comenta que "la metáfora pertenece al juego del lenguaje que gobierna la acción de dar un nombre" (Ricoeur 2006, 60). 
Debe constituirse un nuevo código compartido, un nuevo nombrar las cosas y la realidad, nombrar que nace de la interrogación y la creatividad. Y esta creatividad tiene que ver con los sueños y con el simbolismo de lo nuevo, de la apertura a una nueva racionalidad y a un rescate de la sapiencialidad que nace de las experiencias de la infancia. Creemos que ello constituye una forma de superación de antiguas lógicas de construcción de la historia desde el mundo adulto, de manera de reconocer cómo en la infancia también ocurre una formulación de otras formas de relacionarse con los otros, consigo mismo o con el ambiente. Por ello G. Bachelard considera que la ensoñación de la infancia "es una ensoñación de expansión” (Bachelard 2014, 151). Por ello, este autor considera que, aunque la persona crezca, aun así, permanece en ella el recuerdo vivo de la niñez, y que ella solo se actualiza en una existencia poética.

\section{CENTRALIDAD DE LA IMAGINACIÓN POÉTICA EN LA CONSTRUCCIÓN DE UNA NUEVA EPISTEMOLO- GÍA CON ROSTRO DE NIÑEZ}

Hemos venido reflexionando en torno al concepto de metáfora y cómo ella representa un interesante espacio para pensar el excedente de sentido y la apertura a lo nuevo. La metáfora supera la frialdad de los conceptos de substancia, ente, esencia, y aborda las connotaciones históricas de los sujetos que imaginan una nueva forma de epistemología. La metáfora, dice Beardsley, citado en Ricoeur, "es un poema en miniatura" (Ricoeur 2006, 59). La poética permite acceder a un mundo nuevo, más amplio, más cercano a la sensibilidad, a la estética, los juegos, a la imaginación. Y la infancia, sostenemos, es aquella época vital en la cual se reúnen estas características. Podríamos incluso aventurar que la infancia es poética, porque permite desplegar una serie de posibilidades que antes no estaban. Así lo han hecho notar autores como Alliaud (2017), Bachelard (2014) y Harris (2005). Estos teóricos han puesto acentos en la importancia de la imaginación al momento de pensar la práctica educativa, psicológica o filosófica con la infancia. Se asume una centralidad y un potencial imaginativo en lo poético. Y desde ello es que queremos proponer algunas reflexiones en torno a la filosofía de la educación con rostro de niñez. 
La poética y su lenguaje nos abren a un mundo más amplio. Nos muestran imágenes que escapan de la realidad. Bachelard sostiene que "ante las imágenes que nos proporcionan los poetas, ante esas imágenes que nunca nosotros habríamos podido imaginar por nuestra cuenta, esta inocencia del maravillarse es muy natural. Pero si vivimos con pasividad ese maravillarnos, no participaremos demasiado profundamente en la imaginación creadora" (Bachelard 2014, 14). Es llamativo que el filósofo francés hable de la inocencia del maravillarse, la cual nos permite volver sobre la idea de que la infancia constituye el paradigma de quién debe ser el filósofo, y también de cómo debe actuar el educador. La educación no puede representar una actividad monológica, en la cual la enseñanza se entregue unidireccionalmente sin que los niños o las niñas puedan retroalimentar ese proceso de aprendizaje.

La educación es ante todo un proceso valioso de imaginación, de construcción y de deconstrucción de posibilidades. Y la infancia está en la base de dicho proceso. Por ello el mismo Bachelard pone en relación íntima las ensoñaciones y la infancia. En sus palabras, "un exceso de infancia es un germen de poema. Nos burlaríamos de un padre que por amor a su hijo fuese a descolgar la luna. Pero el poeta no retrocede ante ese gesto cósmico. Sabe, en su ardiente memoria, que se trata de un gesto de infancia. El niño sabe bien que la luna, ese gran pájaro rubio, tiene su nido en alguna parte del bosque" (Bachelard 2014, 152).

Hay en esta imagen cósmica una especie de enfrentamiento entre una lógica que funda el mundo adulto y otro que nace de la infancia y de la poesía. El poeta es como un niño y por ello puede entender la filosofía y la ensoñación de alcanzar al astro menor. En cambio, si un adulto intentase alcanzar la luna el resto de los sujetos se burlarían de él. Hay, con ello, una negación a las posibilidades de ampliación del conocimiento. Parece que, entre la infancia, creativa, lúdica, poética y soñadora y la adultez, fría, calculadora, encerrada, hay una distancia. Creemos que una filosofía de la educación con rostro de niñez debe recuperar el sueño infantil de mirar y tocar la luna. La filosofía es esa disciplina que nos provee de herramientas cuestionadoras que nos sirven para repensar el conocimiento. Hay que escuchar el relato de la infancia que sabe que el pájaro rubio — la luna — se encuentra en alguna parte del bosque. 
Hay que atreverse a entrar al bosque con los niños, porque ellos nos guían. La nueva sociedad comienza con sus juegos, búsquedas y preguntas.

Es por este desafío de entrar al bosque a buscar la luna que creemos que con la infancia despunta la aurora de la nueva mañana. El que hagamos mención de la aurora no es un factor más dentro de un discurso. La aurora representa uno de los primeros tiempos en el orden del día. Está al comienzo de todo, es más, podríamos vincularlo con el momento de la infancia del ser humano. Es más, la infancia posee también un elemento utópico, que va ligado íntimamente a la capacidad de ensoñación que hemos venido retratando anteriormente. Así lo ha hecho notar el filósofo italiano Giorgio Agamben cuando comentando el Pinocho de Collodi sostiene que el país de los juguetes representa "la descripción de esa utópica república infantil, Collodi nos ofrece la imagen de un universo donde todo es juego" (Agamben 2007, 95).

La posibilidad de una renovada pedagogía que recupera la infancia y su imaginación e intencionalidad poética nos permiten valorar las situaciones inesperadas, las rupturas epistemológicas, la sorpresa y lo nuevo. Nos permiten crear una filosofía, una educación, una sociedad más abierta, sensible, expresiva. Los niños nos enseñan y hemos de recuperar ese relato infantil, porque ellos nos demuestran cómo existen capacidades legítimas de esperar, aprender y crear condiciones más libres de sentido. En palabras de Paul Harris "la capacidad para imaginar posibilidades alternativas y para elaborar sus consecuencias aparece tempranamente en el curso del desarrollo infantil y durante toda la vida. Esta capacidad es especialmente obvia en los juegos de simulación de los niños, pero invade y transforma su concepción de la realidad que se encuentra en sí misma, en desarrollo” (Harris 2000, 12).

Los niños nos enseñan cómo esperar, cómo jugar, cómo dejar espacio al asombro, a lo nuevo del día que irrumpe en nuestra sociedad naturalizada. Y es por ello que es necesario continuar creando una cultura del cuidado de la infancia. Los niños y jóvenes son socialmente sujetos vulnerables y vulnerados en sus derechos. No se les ha abierto espacio para que sus relatos de vida puedan ser asimilados por nuestras lógicas adultas y por nuestras prácticas preconcebidas. Los niños y su esperanza aún se ubican en la frontera, pero a pesar de estar en constante estado de vulneración 
reconocemos en ellos la ruptura con lo antiguo, la presencia de la esperanza. En ellos ocurre una ruptura instauradora. En palabras de J. Alison, cuando se posibilita el nacimiento de lo nuevo,

"se produce una ruptura inesperada en el sistema. Significa que ya no hay historia segura, agarrada, no muy satisfactoria pero tampoco del todo insatisfactoria. La ruptura del sistema produce una sacudida increíble porque, exactamente al mismo tiempo que ofrece una salida inesperada del sistema, arroja una luz mucho más drástica y aterradora sobre el sistema, arroja una luz mucho más drástica y aterradora sobre el sistema de lo que se había percibido antes" (Alison 1999, 30).

\section{EL JUEGO COMO POSIBILIDAD DE REFLEXIÓN FILOSÓFICA}

La imaginación supone la creación de espacios propicios para desenvolver la intencionalidad lúdica de la experiencia de la infancia. Es más, si buscamos una definición o una característica fundamental de la niñez es que ella juega. Con ello, queremos adentrarnos ahora en algunas perspectivas sobre cómo el juego constituye una posibilidad de reflexión y de construcción de pensamiento filosófico.

Vivencial, psicológica y antropológicamente, la infancia es la época del juego. Así autores como Florenzano (1993) recuerdan cómo la etapa comprendida entre los cuatro y los cinco años es llamada la edad del juego. Por su parte Paul Harris (2000) recuerda la importancia de los juegos de rol para que los niños puedan ir adquiriendo herramientas para la intersubjetividad y el conocimiento del mundo.

Pero, ¿qué es el juego? ¿Qué gana el niño o la niña jugando? ¿Qué relación existe entre el juego y el conocimiento, el juego y la filosofía? ¿Cómo podemos provocar una pedagogía del juego, que dé espacio al placer, a la alegría, al reconocimiento de los otros? M. Haeussler y A. Torreti distinguen cinco características en la experiencia del juego (Haeussler - Torreti 1996, 102): en primer lugar, estimula el desarrollo 
motor, en cuanto que invita al niño a moverse, saltar, correr, ejercitarse. En segundo lugar, favorece el desarrollo intelectual ya que lleva a explorar el mundo y a repetir determinadas acciones para interiorizar más y mejor las formas de la realidad. En tercer lugar, el juego es importante para el desarrollo emocional ya que el niño puede expresar sus sentimientos y estados anímicos. En penúltimo lugar, el juego favorece el desarrollo social porque los niños aprenden a relacionarse con otros, a integrar a otros, respetar reglas y turnos. Finalmente, el juego contribuye a despertar la curiosidad y crea condiciones educativas para generar un mejor pensamiento simbólico.

El juego posee también una fuerte dimensión de gratuidad y de "posibilidad y potencialidad" (Agamben 2012, 30) en palabras de Agamben. Los niños al jugar despliegan todas sus potencialidades vitales. En palabras del mismo Agamben, “el experimentum potentiae del niño, de hecho, ni siquiera separa su vida biológica: el niño juega con su función fisiológica, o, mejor, la juega, y de este modo, se complace con ella" (Agamben 2012, 30). En el juego acontece la vivencia de la alegría, del placer y de la felicidad y no tanto la producción de bienes tangibles. Por ello, es que pareciera ser que el juego es visto como una pérdida de tiempo desde la lógica económica. Uno debería vivir para producir, no para el ocio. Pero es justamente allí, en esa dinámica gratuita, donde la infancia retrata el rostro más auténtico de la creación del nuevo tiempo. Eso constituye la potencialidad, el poder ser, de la infancia. Desde ella acontece una búsqueda siempre en camino de experiencias nuevas.

En este enfrentamiento de la condición no productiva del juego y la lógica del poder económico, encontramos una segunda oposición, a saber, el mundo de los niños y el mundo de los adultos. En palabras del teólogo brasileño R. Alves,

\footnotetext{
“los niños viven en un mundo dominado por el principio del placer y solamente lo abandonan cuando son forzados por las presiones del deseo y transforman las fantasías que este produce en cosas y actividades, en el mundo lúdico en que habitan. El juego, como actividad que es un fin en sí misma, es nada menos que una expresión de búsqueda interminable de un mundo para ser amado; búsqueda que marca todas las operaciones del ego" (Alves 1982, 131).
} 
Desde esta condición de fantasía, placer y búsqueda, comprendemos también lo que anteriormente decíamos de la búsqueda de la luna del niño y del poeta, propuesta por Bachelard. Es más, creemos que la filosofía también tiene que pasar por esta búsqueda de lo poético y de la fantasía, de la búsqueda, intersubjetividad y desarrollo simbólico y emocional del juego. El juego de los niños debe hacernos aprender a jugar, a crear nuevas realidades, a imaginar nuevas formas de estar en el mundo. Es necesario que podamos educar como profesores a personas felices, normales y sin problemas. Es necesario aprender a disfrutar del conocimiento, a tener la capacidad de crear filosofía, no como repetición mecánica de teorías o doctrinas históricas, sino que como acción lúdica por medio de la cual logramos más humanización.

Y los educadores, que representamos al mundo adulto, hemos de ser capaces de jugar y de comprender cómo nuestra pedagogía y nuestra filosofía - si somos profesores de ella- ha de comprenderse como un juego, como relación gratuita y creativa. En esto, H. Maturana habla que la construcción de la conciencia individual y social del niño se debe articular necesariamente como "una relación de juego" (Maturana 1999, 203). En sus palabras, "es en la relación de juego, en la intimidad del contacto corporal, en la confianza de esa intimidad en el juego, en la aceptación íntima, que el niño o niña desarrolla el respeto por sí mismo y por el otro, precisamente como aspectos naturales de esta relación” (Maturana 1999, 203).

Es llamativa la dimensión corporal que Maturana le adjudica al juego. En ella podemos discernir su dimensión poética, estética y ética. Hay una imaginación en la forma de relacionarnos desde lo lúdico (poética). Hay también una belleza y una forma de relacionarnos, a la vez que existe una percepción de dicha forma, que es natural (estética). Y también un comportamiento específico (ética), un éthos común entre los jugadores, educador y educando, que se actualiza en un espacio de convivencia que es construido gracias a las interacciones de los mismos jugadores. Dicho espacio debe asegurar, en palabras de Maturana, el respeto por sí mismo y por el otro como elementos fundamentales de la vivencia de la democracia. Dicha vivencia se articula en los turnos que los jugadores van respetando de manera de lograr la armonía del juego. Es lo característico de la experiencia lúdica, a saber, el dar espacio a nuevas 
manifestaciones históricas, sociales, educativas, culturales, las cuales tienen el carácter de estar abiertas a las preguntas y nuevas búsquedas.

\section{A MODO DE CONCLUSIÓN, ALGUNAS PISTAS PARA PENSAR EL TRABAJO FILOSÓFICO Y PEDAGÓGICO CON LA INFANCIA Y DESDE LA INFANCIA}

Al finalizar nuestras reflexiones, queremos reseñar algunas pistas para seguir pensando el trabajo filosófico y pedagógico con la infancia y desde la infancia. Sabemos que los trabajos de filosofía para niños, y nosotros agregamos con niños, es un terreno relativamente nuevo que debe seguir un camino de trabajo que creemos se proyecta con buenos resultados.

1. En primer lugar, la capacidad de asumir las preguntas de la infancia. Al comienzo de nuestro artículo rescatábamos las orientaciones que Antonio Faúndez y Paulo Freire ensayaban en torno a la urgencia de una pedagogía de la pregunta. Dicha pedagogía tiene como base el desarrollo filosófico, en donde los niños y niñas son el modelo del auténtico filósofo. Rescatar las preguntas de la niñez implica reconocer cómo ellos son sujetos activos en la construcción del conocimiento. Y a la vez, en negativo, reconocer críticamente que el mundo adulto ha considerado culturalmente que los niños no tienen experiencias significativas de búsquedas, preguntas y conocimiento.

Creemos que ello responde a la práctica de la llamada comunidad de indagación propuesta por M. Lipman en la filosofía para niños. La comunidad de indagación supone practicar el respeto mutuo y la búsqueda participada en torno a un tema común que el educador propone a los niños. Las respuestas u opiniones que surgen de los pequeños participantes, entre más variadas, más significativas. La comunidad no busca la homogenización del conocimiento, sino la participación efectiva a través de preguntas y respuestas como motor auténtico del logro de un conocimiento significativo. 
2. En segundo lugar, la importancia de construir una filosofía de la educación a partir de la racionalidad metafórica. La filosofía de la educación indaga en los elementos que van más allá del fenómeno educativo en sí. Trata de adentrarse en otras formas de enseñanza y aprendizaje a través de la filosofía, de las ciencias del lenguaje y de los abordajes culturales. Entre ellos, hemos reconocido con Ricoeur cómo la metáfora representa una forma de excedente de sentido, un pequeño poema, una experiencia creativa de estar en el mundo.

3. Esta creatividad apuesta por un dar un mayor espacio a lo corporal, a la sensibilidad, al juego, a la poesía, a la belleza, a la música y a la danza. Es la imaginación e intencionalidad poética de la cual habla G. Bachelard. El conocimiento filosófico desde la infancia recurre a nuevas formas de relacionarse con el mundo. En palabras de Otto Maduro, es necesario comprender cómo el conocimiento se puede definir como "imaginación relacionadora" (Maduro 1982, 122). Gracias a dicha intuición, estamos en condiciones de caracterizar lo epistémico como una actitud dinámica de diálogo entre los participantes de una comunidad. Se viene a superar, por tanto, una lógica de pasividad en el conocimiento, una metáfora muerta en palabras de Ricoeur, o una burla hacia el que quiere alcanzar la luna en la bella imagen de Bachelard. Finalmente, gracias a dicha imaginación relacionadora, "el conocimiento intervendría activamente en la realidad diseñando ensayos para ver hasta qué punto esas relaciones imaginadas son capaces o no de dar cuenta de la experiencia de lo real" (Maduro 1982, 122).

4. Estas nuevas formas de creación de lo real, estos ensayos y espacios que se crean gracias a la interacción de los sujetos, se articulan en la experiencia del juego. Lo interesante del juego es que da espacio a distintas posibilidades, ya sean motoras, intelectuales, interpersonales, emocionales o culturales. También filosóficas, incluso teológicas como hemos visto en los planteamientos de R. Alves o N. Panotto. El juego es transversal a la experiencia humana, y es necesario asumirlo desde la comprensión que él permite lo gratuito, la creatividad y la libertad en la interacción de los jugadores que, como hemos visto, tienen acercamientos poéticos, estéticos y éticos. Incluso pueden asumirse como imagen de una comunidad democráctica que respeta turnos en la práctica del juego. 
Hay, incluso, una racionalidad educativa en la experiencia del juego, la cual exige que los educadores, representantes del mundo adulto, se atrevan a jugar y a crear nuevas formas de aprendizaje más humanizadoras con la infancia, los jóvenes y todos aquellos que quieran ayudar a despertar la aurora del nuevo día. A. Alliaud reconoce cómo la experiencia del diálogo y la interacción del conocimiento están muy vinculadas a la experiencia del juego. En sus palabras,

"al jugar los niños repiten (y hasta disfrutan al hacerlo) determinadas acciones, pero en esas mismas repeticiones, van inventando, van creando [...] De este modo, la dinámica del juego en la formación artesanal adquiere relevancia y protagonismo en el presente, donde se trata de que la formación habilite y otorgue las capacidades y habilidades para crear, imaginar, improvisar, afrontar la incertidumbre, lo no previsto, que es en definitiva lo opuesto a predecir, controlar, aplicar" (Alliaud 2017, 112-112). 


\section{Bibliografía}

Agamben, Giorgio. 2007. Infancia e historia. Destrucción de la experiencia y origen de la historia. Buenos Aires: Adriana Hidalgo Editora.

Agamben, Giorgio. 2012. Teología y lenguaje. Del poder de Dios al juego de los niños. Buenos Aires: La Cuarenta.

Alliaud, Andrea. 2017. Los artesanos de la enseñanza. Acerca de la formación de maestros con oficio. Buenos Aires: Paidós.

Alison, James. 1999. El retorno de Abel: Huellas de la imaginación escatológica. Madrid: Herder.

Alves, Rubem. 1982. La teología como juego. Buenos Aires: Ediciones La Aurora.

Bachelard, Gastón. 2014. Poética de la ensoñación. México D.F: FCE.

Carbullanca, César. 2014. "Mito y logos. Nuevos caminos de la hermenéutica latinoamericana”. Estudos de Religao. Vol. 28, n¹, 135-156.

De Certeau, Michel. 2006. La debilidad de creer. Buenos Aires: Katz.

Faúndez, Antonio - Freire, Paulo. 2014. Por una pedagogía de la pregunta. Crítica a una educación basada en respuestas a preguntas inexistentes. Buenos Aires: Siglo XXI Editores.

García Morente, Manuel. 1998. Lecciones preliminares de filosofía. Buenos Aires: Losada.

Haeuessler, Isabel - Torreti, Alejandra. 1996. Familia y desarrollo infantil. Bogotá: CELAM-UNICEF-SELACC.

Harris, Paul. 2000. El funcionamiento de la imaginación. Buenos Aires: Fondo de Cultura Económica.

Maduro, Otto. 1982. Mapas para la fiesta. Reflexiones latinoamericanas sobre la crisis y el conocimiento. Buenos Aires: Centro Nueva Tierra.

Maturana, Humberto. 1999. Transformación en la convivencia. Santiago: Dolmen.

Panotto, Nicolás. 2016. De juegos que hablan de Dios. Hacia una teología desde la niñez latinoamericana. Guayaquil: Sociedades Bíblicas Unidas en Ecuador.

Ricoeur, Paul. 2006. Teoría de la interpretación. Discurso y excedente de sentido. México D. F: Siglo XXI Editores. 